\title{
PELABELAN HARMONIS GANJIL PADA AMALGAMASI GRAF KINCIR ANGIN BELANDA
}

\author{
Fery Firmansah $^{1)^{*}}$, Muhammad Wahid Syaifuddin ${ }^{2)}$ \\ Prodi Pendidikan Matematika, FKIP, Universitas Widya Dharma Klaten, 57438 \\ *feryfirmansah@unwidha.ac.id
}

\begin{abstract}
Abstrak
Graf harmonis ganjil adalah graf yang memenuhi sifat pelabelan harmonis ganjil. Amalgamasi dua graf kincir angin belanda adalah graf yang dibentuk dari operasi amalgamasi dua graf kincir angin belanda dengan graf lintasan. Amalgamasi $k$ graf kincir angin belanda adalah graf yang dibentuk dari operasi amalgamasi $k$ graf kincir angin belanda dengan $k-1$ graf lintasan. Pada makalah ini penulis akan mengkonstruksi amalgamasi dua graf kincir angin belanda dan amalgamasi $k$ graf kincir angin belanda, lebih lanjut penulis akan menunjukkan bahwa amalgamasi dua graf kincir angin belanda dan amalgamasi $k$ graf kincir angin belanda adalah graf harmonis ganjil.
\end{abstract}

Kata Kunci: amalgamasi, graf harmonis ganjil, graf kincir angin belanda, pelabelan

\section{PENDAHULUAN}

Pelabelan graf merupakan topik penelitian matematika kombinatorik yang berkembang sangat pesat pada beberapa tahun belakangan ini. Diperkenalkan sejak tahun 1963 oleh Sedlacelk dan terus berkembang sampai sekarang, Gallian (2016) telah mengumpulkan banyak hasil penelitian tentang pelabelan graf. Salah satu topik pelabelan graf yang sedang hangat diperbincangkan adalah pelabelan harmonis ganjil yang diperkenalkan oleh Liang dan Bai (2009). Pelabelan graf pada dasarnya memberikan label berupa bilangan bulat positif pada elemen suatu graf yaitu simpul, busur atau kombinasinya dengan sifat dan aturan tertentu.

Berikut definisi dari graf harmonis ganjil oleh Liang dan Bai (2009). Graf $G(p, q)$ dengan $p=|V(G)|$ dan $q=|E(G)|$ adalah graf harmonis ganjil jika graf $G(p, q)$ mempunyai fungsi pelabelan simpul $f: V(G) \rightarrow\{0,1,2,3, \ldots, 2 q-1\}$ yang bersifat injektif sedemikian sehingga menginduksi fungsi pelabelan busur $f^{*}: E(G) \rightarrow\{1,3,5,7, \ldots, 2 q-1\} \quad$ yang bersifat bijektif yang didefinisikan oleh $f^{*}(x y)=f(x)+f(y)$. Pada paper yang sama Liang dan Bai (2009) telah 
membuktikan beberapa sifat dari graf harmonis ganjil yaitu jika $G(p, q)$ adalah graf harmonis ganjil maka graf $G(p, q)$ adalah graf bipartit dan memenuhi $2 \sqrt{q} \leq$ $p \leq 2 q-1$.

Beberapa kelas graf yang sudah dibuktikan merupakan graf harmonis ganjil dapat dilihat pada penelitian dari Vaidya dan Shah (2012), Alyani, dkk (2013), Saputri, dkk (2013), Abdel-Aal (2014), Jeyanthi, dkk (2015), Firmansah dan Sugeng (2015), Firmansah (2016), dan Firmansah dan Yuwono (2017).

Pada penelitian tahun 2015 Firmansah dan Sugeng telah memperkenalkan graf kincir angin belanda $C_{4}^{(k)}$ dengan $k \geq 1$ yaitu graf yang dibentuk dari $k$ graf lingkaran $C_{4}$ yang dihubungkan dengan sebuah simpul pusat persekutuan. Lebih lanjut dalam paper yang sama Firmansah dan Sugeng (2015) telah membuktikan bahwa graf kincir angin belanda $C_{4}^{(k)}$ dan gabungan graf kincir angin belanda $C_{4}^{(k)} \cup C_{4}^{(k)}$ adalah graf harmonis ganjil. Peneliti tertarik untuk melanjutkan penelitian ini dengan melakukan operasi amalgamasi pada graf kincir angin belanda.

Operasi amalgamasi dari graf $G_{1}$ dan graf $G_{2}$ didefisinikan sebagai berikut. Operasi amalgamasi dari graf $G_{1}$ dengan $V\left(G_{1}\right)=\left\{a_{i} \mid i=1,2,3, \ldots, n\right\}$ dan graf $G_{2}$ dengan $V\left(G_{2}\right)=\left\{b_{j} \mid j=1,2,3, \ldots, m\right\}$ adalah graf $G_{1} * G_{2}$ yang diperoleh dengan menggabungkan simpul $a_{i}$ dan simpul $b_{j}$ menjadi satu simpul $c_{l}$ sehingga diperoleh $V\left(G_{1} * G_{2}\right)=\left\{c_{l} \mid l=1,2,3, \ldots, n+m-1\right\}$. Definsi operasi amalgamasi dari graf $G_{1} * G_{2}$ diperumum untuk operasi amalgamasi graf $G_{1} * G_{2} * \ldots * G_{k}$.

Pada makalah ini penulis akan mengkonstruksi amalgamasi dua graf kincir angin belanda $C_{4}^{(k)} * P_{2} * C_{4}^{(k)}$ dengan $k \geq 1$ dan amalgamasi $k$ graf kincir angin belanda $C_{4}^{(r)} * P_{2} * C_{4}^{(r)} * \ldots * C_{4}^{(r)}$ dengan $k \geq 1$ dan $r \geq 1$. Lebih lanjut pada makalah ini penulis akan menunjukkan bahwa amalgamasi dua graf kincir angin belanda $C_{4}^{(k)} * P_{2} * C_{4}^{(k)}$ dengan $k \geq 1$ dan amalgamasi $k$ graf kincir angin belanda $C_{4}^{(r)} * P_{2} * C_{4}^{(r)} * \ldots * C_{4}^{(r)}$ dengan $k \geq 1$ dan $r \geq 1$ adalah graf harmonis ganjil.

\section{METODE PENELITIAN}

Penelitian ini merupakan penelitian kualitatif berjenis pengembangan teoritik. Penelitian ini akan mengembangkan teori pelabelan graf khususnya sifat-sifat baru dari graf harmonis ganjil yang dinyatakan dalam teorema.

Tahapan yang dilakukan dalam penelitian sebagai berikut. Tahapan awal adalah tahapan kajian literatur yaitu mengkaji sebanyak mungkin informasi dari penelitian terdahulu untuk keperluan identifikasi masalah. Selanjutnya, tahapan investigasi penelitian yang terdiri kajian terhadap sifat-sifat khusus dari suatu graf sampai tebentuknya teorema. Tahapan akhir adalah verifikasi hasil yang disajikan dalam teorema yang dilengkapi dengan bukti matematis

\section{HASIL DAN PEMBAHASAN}

Bagian ini akan diberikan beberapa definisi yang dibutuhkan dan sifat-sifat baru yang dinyatakan dalam teorema yang disertai dengan pembuktian matematika yang sistematis. Untuk mempermudah pemahaman pada bagian akhir diberikan contoh pelabelan harmonis ganjil pada kelas graf yang sederhana yang merupakan hasil operasi amalgamasi graf. 
Fery Firmansyah dan Muhammad W. S : Pelabelan Harmonis Ganjil Pada Amalgamasi Graf Kincir Angin Belanda

FIBONACCI : Jurnal Pendidikan Matematika dan Matematika. Vol. 4 (1), pp: 37-46.

Definisi 1. Amalgamasi dua graf kincir angin belanda $C_{4}^{(k)} * P_{2} * C_{4}^{(k)}$ dengan $k \geq 1$ adalah graf yang dibentuk dari operasi amalgamasi dua graf kincir angin belanda $C_{4}^{(k)}$ yang dihubungkan dengan graf lintasan $P_{2}$.

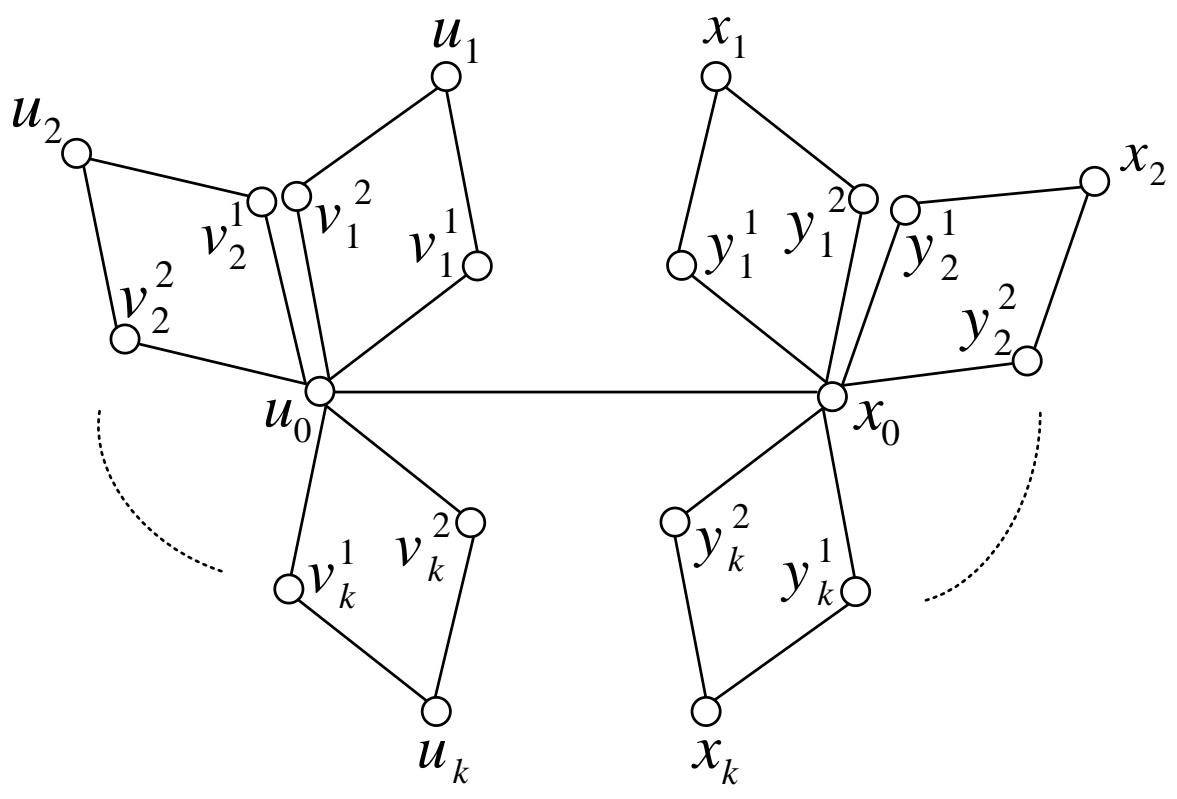

Gambar 1. Konstruksi amalgamasi dua graf kincir angin belanda $C_{4}^{(k)} * P_{2} * C_{4}^{(k)}$

Berdasarkan Gambar 1 diperoleh amalgamasi dua graf kincir angin belanda himpunan simpul dan himpunan busur dari $\quad C_{4}^{(k)} * P_{2} * C_{4}^{(k)}$ sebagai berikut:

$V\left(C_{4}^{(k)} * P_{2} * C_{4}^{(k)}\right)=\left\{u_{0}\right\} \cup\left\{v_{i}^{j} \mid 1 \leq i \leq k, j=1,2\right\} \cup\left\{u_{i} \mid 1 \leq i \leq k\right\} \cup\left\{x_{0}\right\} \cup$

$\left\{y_{i}^{j} \mid 1 \leq i \leq k, j=1,2\right\} \cup\left\{y_{i} \mid 1 \leq i \leq k\right\}$ dan

$E\left(C_{4}^{(k)} * P_{2} * C_{4}^{(k)}\right)=\left\{u_{0} v_{i}^{j} \mid 1 \leq i \leq k, j=1,2\right\} \cup\left\{v_{i}^{j} u_{i} \mid 1 \leq i \leq k, j=1,2\right\} \cup\left\{u_{0} x_{0}\right\} \cup$ $\left\{x_{0} y_{i}{ }^{j} \mid 1 \leq i \leq k, j=1,2\right\} \cup\left\{y_{i}{ }^{j} x_{i} \mid 1 \leq i \leq k, j=1,2\right\}$.

Definisi 2. Amalgamasi $k$ graf kincir angin belanda $C_{4}^{(r)} * P_{2} * C_{4}^{(r)} * \ldots * C_{4}^{(r)}$ dengan $k \geq 1$ dan $r \geq 1$ adalah graf yang dibentuk dari operasi amalgamasi $k$ graf kincir angin belanda $C_{4}^{(r)}$ yang dihubungkan dengan $k-1$ graf lintasan $P_{2}$. 


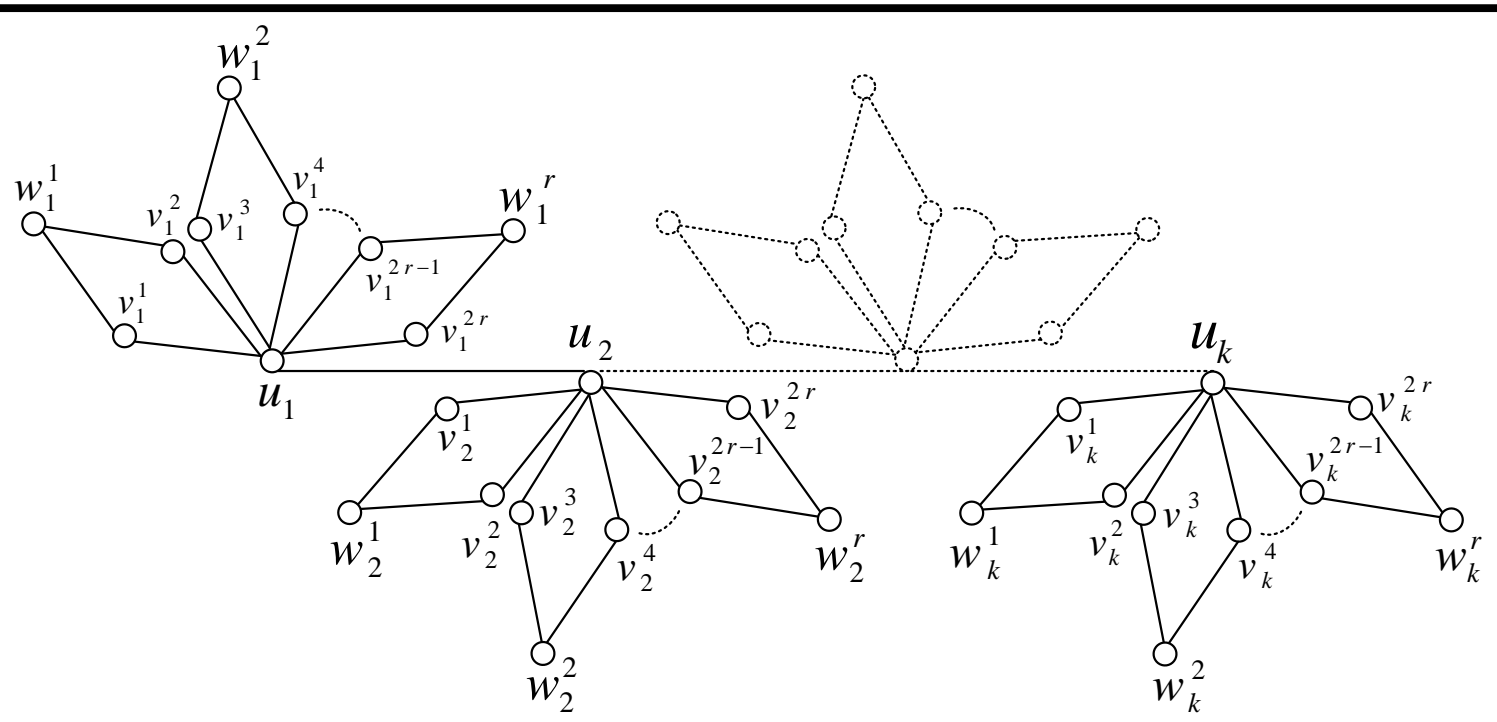

Gambar 2. Konstruksi amalgamasi $k$ graf kincir angin belanda $C_{4}^{(r)} * P_{2} * C_{4}^{(r)} * \ldots * C_{4}^{(r)}$

Berdasarkan Gambar 2 diperoleh amalgamasi $k$ graf kincir angin belanda himpunan simpul dan himpunan busur dari $C_{4}^{(r)} * P_{2} * C_{4}^{(r)} * \ldots * C_{4}^{(r)}$ sebagai berikut:

$V\left(C_{4}^{(r)} * P_{2} * C_{4}^{(r)} * \ldots * C_{4}^{(r)}\right)=\left\{u_{i} \mid 1 \leq i \leq k\right\} \cup\left\{v_{i}{ }^{j} \mid 1 \leq i \leq k, 1 \leq j \leq 2 r\right\} \cup$

$\left\{w_{i}{ }^{j} \mid 1 \leq i \leq k, 1 \leq j \leq r\right\}$ dan

$E\left(C_{4}^{(r)} * P_{2} * C_{4}^{(r)} * \ldots * C_{4}^{(r)}\right)=$

$\left\{u_{i} v_{i}{ }^{j} \mid 1 \leq i \leq k, 1 \leq j \leq 2 r\right\} \cup\left\{v_{i}{ }^{2 j-1} w_{i}{ }^{j} \mid 1 \leq i \leq k, 1 \leq j \leq r\right\} \cup$

$\left\{v_{i}{ }^{2 j} w_{i}^{j} \mid 1 \leq i \leq k, 1 \leq j \leq r\right\} \cup\left\{u_{i} u_{i+1} \mid 1 \leq i \leq k-1\right\}$.

Teorema 3. Amalgamasi dua graf kincir angin belanda $C_{4}^{(k)} * P_{2} * C_{4}^{(k)}$ dengan $k \geq 1$ adalah graf harmonis ganjil.

Bukti.

Berdasarkan definisi himpunan simpul dan himpunan busur dari $C_{4}^{(k)} *$ $P_{2} * C_{4}^{(k)} \quad$ diperoleh $\quad p=\mid V\left(C_{4}^{(k)} * P_{2} *\right.$

$f\left(u_{0}\right)=0$

$f\left(v_{i}^{j}\right)=4 i+2 j-5,1 \leq i \leq k, j=1,2$

$f\left(u_{i}\right)=12 k-8 i+6,1 \leq i \leq k$

$f\left(x_{0}\right)=4 k+1$

$f\left(y_{i}^{j}\right)=4 i+2 j-4,1 \leq i \leq k, j=1,2$

$f\left(x_{i}\right)=16 k-8 i+5,1 \leq i \leq k$

$$
\begin{aligned}
& \left.C_{4}^{(k)}\right) \mid=6 k+2 \text { dan } q=\mid E\left(C_{4}^{(k)} * P_{2} *\right. \\
& \left.C_{4}^{(k)}\right) \mid=8 k+1 .
\end{aligned}
$$

Didefinisikan fungsi pelabelan simpul $f: V\left(C_{4}^{(k)} * P_{2} * C_{4}^{(k)}\right) \rightarrow\{0,1,2,3 \ldots, 16 k+$ $1\}$ sebagai berikut: 
Fery Firmansyah dan Muhammad W. S : Pelabelan Harmonis Ganjil Pada Amalgamasi Graf Kincir Angin

FIBONACCI : Jurnal Pendidikan Matematika dan Matematika. Vol. 4 (1), pp: 37-46.

Berdasarkan persamaan (1), (2), (3),

setelah dilabel sebagai berikut:

(4), (5), dan (6) diperoleh himpunan simpul

$f\left(V\left(C_{4}^{(k)} * P_{2} * C_{4}^{(k)}\right)\right)=\{0\} \cup\{1,5,9, \ldots, 4 k-3,3,7,11, \ldots, 4 k-1\}$

$\cup\{12 k-2,12 k-10,12 k-18, \ldots, 4 k+11,4 k+6\} \cup\{4 k+1\}$

$\cup\{2,6,10,12, \ldots, 4 k-2,4,8,12, \ldots, 4 k\}$

$\cup\{16 k-3,16 k-11,16 k-19, \ldots, 8 k+13,8 k+5\}$

$=\{0,1,2,3,4, \ldots, 16 k-3\}$

Diperoleh

$$
f\left(V\left(C_{4}^{(k)} * P_{2} * C_{4}^{(k)}\right)\right) \subseteq
$$

$\left.C_{4}^{(k)}\right) \rightarrow\{1,3,5,7, \ldots, 16 k+1\}$

yang

$\{0,1,2,3 \ldots, 16 k+1\}$ dan label yang berbeda pada setiap simpul akibatnya didefinisikan oleh $f^{*}(x y)=f(x)+f(y)$, sebagai berikut:

fungsi pelabelan simpul $f$ bersifat injektif.

Selanjutnya diberikan fungsi

pelabelan pelabelan busur $f^{*}: E\left(C_{4}^{(k)} * P_{2} *\right.$

$f^{*}\left(u_{0} v_{i}{ }^{j}\right)=4 i+2 j-5,1 \leq i \leq k, j=1,2$

$f^{*}\left(v_{i}^{j} u_{i}\right)=12 k-4 i+2 j+1,1 \leq i \leq k, j=1,2$

$f^{*}\left(u_{0} x_{0}\right)=4 k+1$

$f^{*}\left(x_{0} y_{i}^{j}\right)=4 k+4 i+2 j-3,1 \leq i \leq k, j=1,2$

$f^{*}\left(y_{i}{ }^{j} x_{i}\right)=16 k-4 i+2 j+1,1 \leq i \leq k, j=1,2$

Berdasarkan persamaan (7), (8), (9), (10), dan (11) diperoleh himpunan busur setelah dilabel sebagai berikut:

$$
\begin{aligned}
& f^{*}\left(E\left(C_{4}^{(k)} * P_{2} * C_{4}^{(k)}\right)\right)=\{1,5,9, \ldots, 4 k-3,3,7,11, \ldots, 4 k-1\} \\
& \cup\left\{\begin{array}{l}
12 k-1,12 k-5,12 k-9, \ldots, 8 k+7,8 k+3, \\
12 k+1,12 k-3,12 k-7, \ldots, 8 k+9,8 k+5
\end{array}\right\} \\
& \cup\{4 k+1\} \\
& \cup\left\{\begin{array}{l}
4 k+3,4 k+7,4 k+11, \ldots, 8 k-5,8 k-1, \\
4 k+5,4 k+9,4 k+13, \ldots, 8 k-3,8 k+1
\end{array}\right\} \\
& \cup\left\{\begin{array}{l}
16 k-1,16 k-5,16 k-9, \ldots, 12 k+7,12 k+3, \\
16 k+1,16 k-3,16 k-7, \ldots, 12 k+9,12 k+5
\end{array}\right\} \\
& =\{1,3,5,7, \ldots, 16 k+1\}
\end{aligned}
$$


Diperoleh $\quad f^{*}\left(E\left(C_{4}^{(k)} * P_{2} * C_{4}^{(k)}\right)\right)=$ $\{1,3,5,7, \ldots, 16 k+1\}$ dan label yang berbeda pada setiap busur dan akibatnya fungsi pelabelan busur $f^{*}$ bersifat bijektif.

Telah ditunjukkan bahwa fungsi pelabelan simpul $f$ bersifat injektif sedemikian sehingga menginduksi fungsi pelabelan busur $f^{*}$ yang bersifat bijektif. Akibatnya amalgamasi dua graf kincir angin belanda $C_{4}^{(k)} * P_{2} * C_{4}^{(k)}$ dengan $k \geq 1$ adalah graf harmonis ganjil

Teorema 4. Amalgamasi $k$ graf kincir angin belanda $C_{4}^{(r)} * P_{2} * C_{4}^{(r)} * \ldots * C_{4}^{(r)}$ dengan $k \geq 1$ dan $r \geq 1$ adalah graf harmonis ganjil.

\section{Bukti.}

Berdasarkan definisi himpunan simpul dan himpunan busur dari $C_{4}^{(r)} * P_{2} * C_{4}^{(r)} * \ldots *$ $C_{4}^{(r)}$ diperoleh $p=\mid V\left(C_{4}^{(r)} * P_{2} * C_{4}^{(r)} *\right.$ $\left.\ldots * C_{4}^{(r)}\right) \mid=3 r k+k$ dan $q=\left|E\left(C_{4}^{(r)} * P_{2} * C_{4}^{(r)} * \ldots * C_{4}^{(r)}\right)\right|=$ $4 r k+k-1$.

Didefinisikan fungsi pelabelan simpul $f: V\left(C_{4}^{(r)} * P_{2} * C_{4}^{(r)} * \ldots * C_{4}^{(r)}\right) \rightarrow$ $\{0,1,2,3 \ldots, 8 r k+2 k-3\}$ sebagai berikut:

$$
\begin{aligned}
& f\left(u_{i}\right)= \begin{cases}(2 r+1) i-(2 r+1), & 1 \leq i \leq k, i=\text { ganjil } \\
(2 r+1) i-1, & 1 \leq i \leq k, i=\text { genap }\end{cases} \\
& f\left(v_{i}^{j}\right)= \begin{cases}(2 r+1) i+2 j-(2 r+2), & 1 \leq i \leq k, i=\text { ganjil, } 1 \leq j \leq 2 r \\
(2 r+1) i+2 j-(4 r+2), & 1 \leq i \leq k, i=\text { genap, } 1 \leq j \leq 2 r\end{cases} \\
& f\left(w_{i}{ }^{j}\right)= \begin{cases}(4 r+2) k+(2 r-1) i-8 j+(2 r+3), & 1 \leq i \leq k, i=\text { ganjil, } 1 \leq j \leq r \\
(4 r+2) k+(2 r-1) i-8 j+(4 r+3), & 1 \leq i \leq k, i=\text { genap, } 1 \leq j \leq r\end{cases}
\end{aligned}
$$

Berdasarkan persamaan (12), (13) dan (14) diperoleh label yang berbeda pada setiap simpul dan $f\left(V\left(C_{4}^{(r)} * P_{2} * C_{4}^{(r)} *\right.\right.$ $\left.\left.\ldots * C_{4}^{(r)}\right)\right) \subseteq\{0,1,2,3 \ldots, 8 r k+2 k-3\}$ akibatnya fungsi pelabelan simpul $f$ bersifat injektif.
Selanjutnya diberikan fungsi pelabelan busur $f^{*}: E\left(C_{4}^{(r)} * P_{2} * C_{4}^{(r)} * \ldots *\right.$ $\left.C_{4}^{(r)}\right) \rightarrow\{1,3,5,7, \ldots, 8 r k+2 k-3\} \quad$ yang didefinisikan oleh $f^{*}(u v)=f(u)+f(v)$, sebagai berikut:

$$
\begin{aligned}
& f^{*}\left(u_{i} v_{i}^{j}\right)=(4 r+2) i+2 j-(4 r+3), 1 \leq i \leq k, 1 \leq j \leq 2 r \\
& f^{*}\left(v_{i}^{2 j-1} w_{i}^{j}\right)=(4 r+2) k+4 r i-4 j-1,1 \leq i \leq k, 1 \leq j \leq r \\
& f^{*}\left(v_{i}^{2 j} w_{i}{ }^{j}\right)=(4 r+2) k+4 r i-4 j+1,1 \leq i \leq k, 1 \leq j \leq r \\
& f^{*}\left(u_{i} u_{i+1}\right)=(4 r+2) i-1,1 \leq i \leq k-1
\end{aligned}
$$

Berdasarkan persamaan (15), (16), (17), dan (18) diperoleh himpunan busur setelah dilabel sebagai berikut: 


$$
\begin{aligned}
& f^{*}\left(E\left(C_{4}^{(r)} * P_{2} * C_{4}^{(r)} * \ldots * C_{4}^{(r)}\right)\right)=\{1,3,5,7, \ldots, 8 r k+2 k-3\} \\
& =\left\{\begin{array}{c}
1,3,5,7,9,11,13,15,17,19,21,23,25,27,29,31,33,35,37,39,41, \ldots, 4 r-3,4 r-1, \\
4 r+3,4 r+5,4 r+7,4 r+9,4 r+11,4 r+13,4 r+15,4 r+17, \ldots, 8 r-1,8 r+1, \\
8 r+5,8 r+7,8 r+9,8 r+11,8 r+13,8 r+15,8 r+17,8 r+19, \ldots, 12 r+1,12 r+3, \\
12 r+7,12 r+9,12 r+11,12 r+13,12 r+15,12 r+17,12 r+19, \ldots, 16 r+3,16 r+5, \\
\ldots, \\
4 r k+2 k-4 r-1,4 r k+2 k-4 r+1,4 r k+2 k-4 r+3, \ldots, 4 r k+2 k-5,4 r k+2 k-3
\end{array}\right\} \\
& \cup\left\{\begin{array}{c}
4 r k+2 k+4 r-5,4 r k+2 k+4 r-9,4 r k+2 k+4 r-13, \ldots, 4 r k+2 k-1, \\
4 r k+2 k+8 r-5,4 r k+2 k+8 r-9,4 r k+2 k+8 r-13, \ldots, 4 r k+2 k+4 r-1, \\
4 r k+2 k+12 r-5,4 r k+2 k+12 r-9,4 r k+2 k+12 r-13, \ldots, 4 r k+2 k+8 r-1, \\
4 r k+2 k+16 r-5,4 r k+2 k+16 r-9,4 r k+2 k+16 r-13, \ldots, 4 r k+2 k+12 r-1, \\
\ldots, \\
8 r k+2 k-5,8 r k+2 k-9,8 r k+2 k-13, \ldots, 8 r k+2 k-4 r+3,8 r k+2 k-4 r-1
\end{array}\right\} \\
& \cup\left\{\begin{array}{c}
4 r k+2 k+4 r-3,4 r k+2 k+4 r-7,4 r k+2 k+4 r-11, \ldots, 4 r k+2 k+1, \\
4 r k+2 k+8 r-3,4 r k+2 k+8 r-7,4 r k+2 k+8 r-11, \ldots, 4 r k+2 k+4 r+1, \\
4 r k+2 k+12 r-3,4 r k+2 k+12 r-7,4 r k+2 k+12 r-11, \ldots, 4 r k+2 k+8 r+1, \\
4 r k+2 k+16 r-3,4 r k+2 k+16 r-7,4 r k+2 k+16 r-11, \ldots, 4 r k+2 k+12 r+1, \\
\ldots, \\
8 r k+2 k-3,8 r k+2 k-7,8 r k+2 k-11, \ldots, 8 r k+2 k-4 r+5,8 r k+2 k-4 r+1
\end{array}\right\} \\
& \cup\{4 r+1,8 r+3,12 r+5,16 r+7, \ldots, 4 r k+2 k-8 r-5,4 r k+2 k-4 r-3\} \\
& =\{1,3,5,7, \ldots, 8 r k+2 k-3\}
\end{aligned}
$$

Diperoleh $\quad f^{*}\left(E\left(C_{4}^{(r)} * P_{2} * C_{4}^{(r)} * \ldots *\right.\right.$ $\left.\left.C_{4}^{(r)}\right)\right)=\{1,3,5,7, \ldots, 8 r k+2 k-3\} \quad$ dan label yang berbeda pada setiap busur akibatnya fungsi pelabelan busur $f^{*}$ bersifat bijektif.

Telah ditunjukkan bahwa fungsi pelabelan simpul $f$ bersifat injektif sedemikian sehingga menginduksi fungsi pelabelan busur $f^{*}$ yang bersifat bijektif.
Akibatnya amalgamasi $k$ graf kincir angin belanda $C_{4}^{(r)} * P_{2} * C_{4}^{(r)} * \ldots * C_{4}^{(r)}$ dengan $k \geq 1$ dan $r \geq 1$ adalah graf harmonis ganjil

Contoh. Berikut diberikan kontruksi dan pelebalan harmonis ganjil pada $C_{4}^{(6)} * P_{2} *$ $C_{4}^{(6)} * P_{2} * C_{4}^{(6)} * P_{2} * C_{4}^{(6)} * P_{2} * C_{4}^{(6)} *$ $P_{2} * C_{4}^{(6)} \quad$ pada $\quad$ Gambar 3 . 
FIBONACCI : Jurnal Pendidikan Matematika dan Matematika

Volume 4 No.1 Bulan Juni Tahun 2018

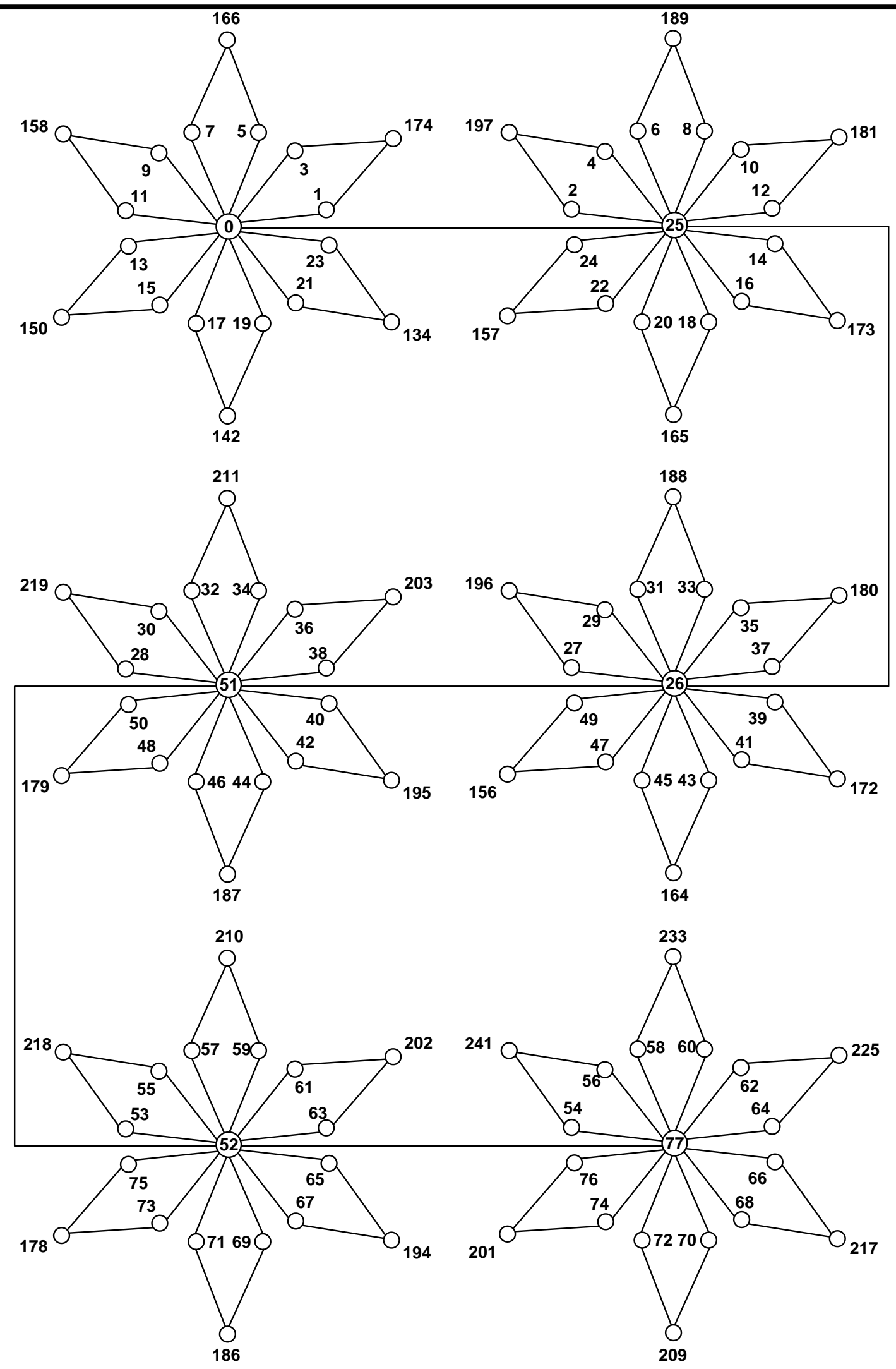

Gambar 3. Pelabelan harmonis ganjil pada $C_{4}^{(6)} * P_{2} * C_{4}^{(6)} * P_{2} * C_{4}^{(6)} * P_{2} * C_{4}^{(6)} * P_{2} *$ $C_{4}^{(6)} * P_{2} * C_{4}^{(6)}$ 


\section{SIMPULAN}

Pada makalah ini telah diperoleh konstruksi dari amalgamasi dua graf kincir angin belanda $C_{4}^{(k)} * P_{2} * C_{4}^{(k)}$ dengan $k \geq 1$ (Definisi 1) dan amalgamasi $k$ graf kincir angin belanda $C_{4}^{(r)} * P_{2} * C_{4}^{(r)} * \ldots *$ $C_{4}^{(r)}$ dengan $k \geq 1$ dan $r \geq 1$ (Definisi 2). Lebih lanjut telah dibuktikan bahwa amalgamasi dua graf kincir angin belanda
$C_{4}^{(k)} * P_{2} * C_{4}^{(k)}$ dengan $k \geq 1$ adalah graf harmonis ganjil (Teorema 3) dan amalgamasi $k$ graf kincir angin belanda $C_{4}^{(r)} * P_{2} * C_{4}^{(r)} * \ldots * C_{4}^{(r)}$ dengan $k \geq 1$ dan $r \geq 1$ adalah graf harmonis ganjil (Teorema 4).

\section{UCAPAN TERIMA KASIH}

Penulis megucapkan terimakasih kepada RISTEK DIKTI sebagai penyandang dana dalam penelitian ini yaitu Hibah Penelitian Dosen Pemula (PDP) pada tahun 2018.

\section{DAFTAR PUSTAKA}

Abdel-Aal, M. E. 2014. "New Families of Odd Harmonious Graphs". International Journal of Soft Computing, Mathematics and Control. Vol. 3(1), pp: 1-13.

Alyani, F., Firmansah, F., Giyarti, W., dan Sugeng, K. A. 2013. "The Odd Harmonious Labeling of $\mathrm{kCn}$-Snake Graphs for Spesific Values of $n$, that is, for $n=4$ and $n=8$ ". Prosiding. Dalam: IndoMS International Conference on Mathemathics and Its Applications, 6-7 November 2013, pp: 225-230.

Firmansah, F. 2016. "Pelabelan Harmonis Ganjil pada Gabungan Graf Ular dan Graf Ular Berlipat". Makalah. Dalam: Konferensi Nasional Matematika dan Pembelajarannya (KNPMP 1), 12 Maret 2016.

Firmansah, F. 2016. "Pelabelan Harmonis Ganjil pada Graf Kincir Angin Double Quadrilateral". Makalah. Dalam: Seminar Nasional Matematika dan Pendidikan Matematika, 5 November 2016.

Firmansah, F. 2017. "The Odd Harmonious Labeling on Variation of the Double Quadrilateral Windmill Graphs”. Jurnal Ilmu Dasar. Vol. 18(2), pp: 109-118.

Firmansah, F., dan Sugeng, K. A. 2015. "Pelabelan Harmonis Ganjil pada Graf Kincir Angin Belanda dan Gabungan Graf Kincir Angin Belanda”. Magistra. Vol. XXVII (94), pp: 56-92.

Firmansah, F. dan Yuwono, M. R. 2017. "Odd Harmonious Labeling on Pleated of the Dutch Windmill Graphs". Jurnal Chauchy - Jurnal Matematika Murni dan Aplikasi. Vol. 4(4), pp: 161-166. 
Firmansah, F. dan Yuwono, M. R. 2017. "Pelabelan Harmonis Ganjil pada Kelas Graf Baru Hasil Operasi Cartesian Product”. Jurnal Matematika Mantik. Vol. 3(2), pp: 87-95.

Firmansah, F. dan Yuwono, M. R. 2017. "Pelabelan Harmonis Ganjil pada Kelas Graf Baru Hasil Operasi Gabungan”. Makalah. Dalam: Seminar Nasional Matematika dan Pendidikan Matematika, 11 November 2017.

Gallian, J. A. 2016. "A Dynamic Survey of Graph Labeling”. The Electronic Journal of Combinatorics, 18. \#DS6.

Jeyanthi, P, Philo, S, dan K. A. Sugeng. 2015. "Odd Harmonious Labeling of Some Some New Families of Graphs”. SUT Journal of Mathematics. Vol. 51(2), pp: 53-65.

Liang, Z., dan Bai, Z. 2009. “On The Odd Harmonious Graphs with Applications”. J. Appl. Math. Comput. Vol. 29, pp: 105-116.

Saputri, G. A., Sugeng, K. A., dan Froncek, D. 2013. "The Odd Harmonious Labeling of Dumbbell and Generalized Prims Graphs", AKCE Int, J. Graphs Comb. Vol. 10 (2) pp: 221-228.

Vaidya, S. K., dan Shah, N. H. 2012. "Odd Harmonious Labeling of Some Graphs". International J. Math. Combin, Vol. 3, pp: 105-112.

Vaidya, S. K., dan Shah, N. H. 2011. "Some New Odd Harmonious Graphs". International Journal of Mathematics and Soft Computing Vol. 1(1), pp: 9-16. 